\title{
General Info: Materials Chemistry and Physics (Materials Chemistry 2020) - International e-Conference
}

Advances in Materials, Physics, and Chemistry Science (Materials Chemistry 2020) is an international conference that aims to bring together scientists, researchers and industrialists from all over the world on a common platform to discuss and share recent advances in Materials, Chemistry, and Physics.

Materials Chemistry 2020 aims to bring together scientists, researchers, and practitioners in order to discuss and share cutting-edge development in the field. Materials Chemistry 2020 provides an ideal platform and opportunity for all the young researchers to connect with eminent Scientists and Industrialists. The Conference is a premier enlightening and networking for all industry stakeholders, policy makers, investors, industry and research community to exchange experiences and challenges related to development and scaling up in the field of Materials Science physics and chemistry.

\section{Web}

https://materialschemistry.researchwaves.com/

\section{Address}

20-22, Wenlock Road, London, England, N1 7GU

\section{Conference Venue}

Online conference (GMT+1, London)

\section{Conference Date}

11-12 September 2020

\section{E-mail}

rina.akean@materialsummits.com

\section{Organized by}

Research Waves Ltd

Web: https://researchwaves.com/

Location: 20-22 Wenlock Road, London, England, N1 7GU

\section{Organizing Committee}

Dr. Raman Singh, Monash University, Australia

Dr. Yuksel AKINAY, Van Yuzuncu Yil University, Turkey

Dr. Celio Albano da Costa Neto, UFRJ, Brasil 

Dr. Yomen Atassi, UHIAST, Damascus, Syria
Dr. Richard Palmer, Swansea University, UK
Dr. Masahiro Yoshimura, National Cheng Kung University, Taiwan
Dr. Timothy Long, Macromolecules Innovation Institute, USA
Dr. Osman Adiguzel, Firat University, Turkey
Dr. M. De Cesare, University of Campania Luigi Vanvitelli, Italy

\section{Conference Hihghlights}

Materials Science and engineering

Physics and Physics Engineering

Chemical and Chemical Engineering

Steels and Heat Treatment

Applied physics

Materials Chemistry

Materials characterization techniques

Polymer Science and Polymeric Materials

Nanomaterials, Nanotechnology and Sensors

Electrical and Magnetic Materials

Optical Materials

Carbon Nanomaterials, devices and technologies

Smart Materials \& Structures

The Future of Piezoelectricity

Bio-materials and Tissue Engineering

Mining and minerology

Advances in Manufacturing, Instrumentation Technology Energy and the Environment Nanotechnology in Healthcare

Nanomedicine and Biomedical Engineering

\section{Keynote Speakers}

Prof. Dr. Masahiro Yoshimura, National Cheng Kung University, Taiwan

Prof. Dr. Swamini Chopra, Department of Mechanical Engineering, M.I.T., India

Prof. Dr. Lucia D'Accolti, University of Bari “Aldo Moro”, via E. Orabona, Italy

Prof. Dr. Adrien Chauvet, The University of Sheffield, UK

Prof. Dr. Richard E. Palmer, Swansea University, UK

Prof. Dr. Nicola Cioffi, University of Bari “Aldo Moro", via E. Orabona, Italy

Prof. Dr. Jow-Lay Huang, National Cheng Kung University, Taiwan

Prof. Dr. Sabu Thomas, Mahatma Gandhi University, Kerala, India

Prof. Dr. Thomas J. Webster, Northeastern University, USA

Prof. Dr. Umberto Berardi, Ryerson University, Toronto, Ontario, Canada

Prof. Dr. Roger M. Leblanc, University of Miami, USA 